\title{
Regulation of the Postsynaptic Cytoskeleton: Roles in Development, Plasticity, and Disorders
}

\author{
Tatyana Svitkina, ${ }^{1}$ Wan-Hsin Lin, ${ }^{2,3}$ Donna J. Webb, ${ }^{2,3,4}$ Ryohei Yasuda, ${ }^{5,6}$ Gary A. Wayman, ${ }^{9,10}$ Linda Van Aelst, ${ }^{11}$ \\ and Scott H. Soderling $6,7,8$ \\ ${ }^{1}$ Department of Biology, The University of Pennsylvania, Philadelphia, Pennsylvania 19104, ${ }^{2}$ Department of Biological Sciences, ${ }^{3}$ Vanderbilt Kennedy \\ Center for Research on Human Development, and ${ }^{4}$ Department of Cancer Biology, Vanderbilt University, Nashville, Tennessee 37235, ${ }^{5}$ Howard Hughes \\ Medical Institute, Departments of ${ }^{6}$ Neurobiology and ${ }^{7}$ Cell Biology, and ${ }^{8}$ Neonatal Perinatal Research Institute, Duke University Medical Center, Durham, \\ North Carolina 27710, ${ }^{9}$ Program in Neuroscience and ${ }^{10}$ Department of Veterinary Comparative Anatomy, Physiology, and Pharmacology, Washington State \\ University, Pullman, Washington 99164, and ${ }^{11}$ Cold Spring Harbor Laboratory, Cold Spring Harbor, New York 11724
}

The small size of dendritic spines belies the elaborate role they play in excitatory synaptic transmission and ultimately complex behaviors. The cytoskeletal architecture of the spine is predominately composed of actin filaments. These filaments, which at first glance might appear simple, are also surprisingly complex. They dynamically assemble into different structures and serve as a platform for orchestrating the elaborate responses of the spine during experience-dependent plasticity. This mini-symposium review will feature ongoing research into how spines are regulated by actin-signaling pathways during development and plasticity. It will also highlight evolving studies into how disruptions to these pathways might be functionally coupled to congenital disorders such as mental retardation.

\section{Introduction}

The capacity of neurons to function within neuronal circuits underlies all our behaviors, thoughts, emotions, and memories. Precise control of the development and location of synapses is critical for accurate neuronal network activity and normal brain function. Most excitatory synapses in the mammalian brain are formed on actin-rich protrusions of the dendritic membrane known as dendritic spines (Nimchinsky et al., 2002; Bourne and Harris, 2008). Dendritic spines are highly dynamic (Matus, 2000), their formation, maturation, and plasticity heavily depend on the actin cytoskeleton remodeling (Ethell and Pasquale, 2005; Cingolani et al., 2008), and many of the key players controlling this process are members of the Rho-family of small GTPases (Matsuzaki et al., 2004; Okamoto et al., 2004; Kopec et al., 2006). These GTPases regulate the assembly and organization of spine actin filaments by controlling the activity of a variety of actinbinding proteins (ABPs). Some ABPs inhibit spine actin filament growth by capping growing actin ends, whereas others oppose the capping of filaments or promote filament polymerization by the nucleation of new filaments (Okada and Soderling, 2009). This balance represents an important regulatory step to rapidly modulate actin dynamics within the spine.

Received Aug. 16, 2010; revised Sept. 23, 2010; accepted Sept. 26, 2010.

This work was supported by the National Institute of Mental Health (MH082808) and National Alliance for Autism Research (L.V.A.); the Hope for Depression Foundation and National Institute of Mental Health (MH086032, G.A.W.); the National Institutes of Health (NIH) (NS059957), March of Dimes, and Dana Foundation (S.H.S.); MH071674 from NIH and S10RR025524 from the National Center for Research Resources at NIH (D.J.W.); NIH Grants GM 70898 and RR 22482 (T.S.); and Howard Hughes Medical Institute funding and National Institute of Neurological Disorders and Stroke Grant R01NS068410 (R.Y.).

Correspondence should be addressed to Scott H. Soderling, Departments of Cell Biology and Neurobiology, Duke University Medical School, Durham, NC 27710. E-mail: s.soderling@cellbio.duke.edu.

DOI:10.1523/JNEUROSCI.4276-10.2010

Copyright $\odot 2010$ the authors $\quad 0270-6474 / 10 / 3014937-06 \$ 15.00 / 0$
Spines are principally thought to spatially coordinate the biochemical signaling cascades that occur in response to presynaptic inputs (Nimchinsky et al., 2002). Mature spines typically have a round head at the tip and a narrow neck that emerges from the dendritic shaft, and they range in size from 0.5 to $2 \mu \mathrm{m}$ in length. While individual spines can vary widely in shape, the morphology of spines is generally classified into three categories: thin, stubby, and mushroom. Recent studies indicate a strong correlation between the actin cytoskeleton, spine morphology, and synaptic strength (Hering and Sheng, 2001; Yuste and Bonhoeffer, 2001; Nimchinsky et al., 2002; Kasai et al., 2003). For example, dendritic spines in hippocampal pyramidal neurons increase and decrease their volume during long-term potentiation (LTP) and depression (LTD), respectively (Matsuzaki et al., 2004; Okamoto et al., 2004; Zhou et al., 2004). This activity-dependent spine structural plasticity is thought to be essential for changing synaptic strength, and caused by reorganization of the actin cytoskeleton. Additionally, a number of human mental retardation (MR) syndromes have been linked to the regulation of the actin cytoskeleton and spine morphology (Ramakers, 2002; Newey et al., 2005). Thus, understanding the signals that instruct the spine cytoskeleton and function is crucial to the understanding of synaptic mechanisms believed to underlie complex behaviors, including learning and memory.

This review will discuss the unique structure of the spine actin cytoskeleton, new insights into how spine actin is regulated, and how disruptions in signaling to spine actin may alter synapse formation, function, and ultimately cognitive ability.

\section{Cytoskeletal organization of neuronal synapses}

(Tatyana Svitkina)

Despite the clear importance of the actin cytoskeleton in the function of excitatory synapses, the underlying structural organi- 
zation of actin filaments at the presynaptic and postsynaptic sides of the synapse are poorly understood, primarily because of their small size and complex organization. To address this question, we have used platinum replica electron microscopy to characterize the cytoskeletal organization and molecular composition of dendritic spines, as well as of their putative precursors, dendritic filopodia, and of presynaptic boutons (Korobova and Svitkina, 2010). Before this study, a common belief was that the head of a spine should contain an Arp2/3 complex-dependent branched network like that found in lamellipodia of migrating cells, whereas the spine neck is likely maintained by an axial actin filament bundle similar to those in filopodia of migrating cells (Halpain, 2000; Rao and Craig, 2000; Tada and Sheng, 2006; Hotulainen et al., 2009). We found that a branched actin filament network containing the Arp $2 / 3$ complex and capping protein, the conventional lamellipodial markers, was a dominant feature of spine heads, as predicted. Presynaptic boutons also contained a very similar branched network. Unexpectedly, however, the spine necks and bases, as well as the shafts of dendritic filopodia, were not composed of tight actin bundles, but instead contained an actin filament network consisting of a combination of branched and intersecting linear actin filaments. This network was immunopositive for the Arp2/3 complex and capping protein, as well as myosin II, a component of contractile actin filament bundles and networks. In contrast, a bundling protein fascin, a marker of conventional filopodia, was not detected in dendritic spines or filopodia, although it was present in growth cone filopodia. Furthermore, dendritic filopodia dynamically emerged from local densities within the dendritic shaft, which by electron microscopy contained branched actin filament networks attached to dendritic microtubules. Based on these findings, we propose that dendritic spine morphogenesis begins from an actin patch that elongates to form a dendritic filopodium. At the onset of spine maturation, the filopodial tip expands via Arp2/3 complexdependent nucleation to form a spine head, which then houses the postsynaptic scaffold of signaling components. The length of the spine is likely modulated by myosin II-dependent contractility of the actin network residing in the spine neck.

The network-like organization of the actin cytoskeleton of dendritic spines and dendritic filopodia may be beneficial for enhancing the plasticity of dendritic protrusions during synapse formation and tuning. However, it is surprising that a tight actin filament bundle is not necessary for the structural support of dendritic filopodia and spine necks, even though it is a key feature of other cylindrical protrusions (Chhabra and Higgs, 2007). Looking for alternative mechanisms that might provide additional structural support for dendritic protrusions, we have analyzed the spectrin-based membrane skeleton. Specifically this work is focused on spectrin $\beta$ III, mutation in which results in a neurodegenerative disorder, spinocerebellar ataxia type 5 (Ikeda et al., 2006; Stankewich et al., 2010). These findings indicate that spectrin $\beta$ III localizes to dendritic spine necks and is important for dendritic spine formation.

\section{VASP induces actin rearrangement in dendritic spines to promote their formation and modulate synaptic strength (Wan-Hsin Lin and Donna J. Webb)}

ABPs that govern the reorganization and structure of actin have been widely studied in non-neuronal cells; however, the role of ABPs in modulating the function of spines and synapses is not well understood. Here, we discuss our recent work on the multifunctional ABP vasodilator-stimulated phosphoprotein (VASP), which shows that it is a critical regulator of spine formation and synaptic function in hippocampal neurons. VASP is comprised of three conserved domains, including an N-terminal Ena/VASP homology 1 (EVH1) domain, a proline-rich domain (PRD), and a C-terminal EVH2 domain. VASP can promote actin polymerization by (1) interacting with the G-actin binding protein profilin through its PRD region to recruit monomeric actin (Reinhard et al., 1995; Kang et al., 1997), and (2) protecting the barbed ends of actin filaments from capping protein, which restrains actin assembly (Gertler et al., 1996; Barzik et al., 2005). The EVH1 domain is important for VASP targeting to actin-rich structures (Bear et al., 2000; Applewhite et al., 2007). We found that endogenous VASP is enriched in spine heads and synapses, and expression of GFP-VASP increases the spine and synaptic density as well as the spine head size (Lin et al., 2010). In addition, VASP expression results in a significant increase in the amount of actin filaments and uncapped barbed ends available for further actin polymerization in spines, suggesting that VASP-mediated actin assembly underlies the formation of these structures. Knockdown of endogenous VASP by siRNAs decreases the number of spines and synapses, and this defect can be rescued by expression of siRNA-resistant VASP. To assess the critical region of VASP that mediates its localization and function in spines, we generated various deletion domain constructs and expressed them in neurons. These results showed that the EVH1 and EVH2 domains were essential for VASP targeting and function in spines, while the PRD was dispensable.

The effect of VASP on actin assembly and spine head enlargement prompted us to further examine the role of this protein in regulating synaptic function. Using immunocytochemistry, we found that VASP increases the amount of postsynaptic density (PSD) scaffolding proteins, including PSD95, Homer, and Shank, in spines. Moreover, VASP increases the number and retention of GluR1-containing AMPA receptors (AMPARs) in spines. VASP affects the distribution of the postsynaptic components to ultimately potentiate AMPAR-mediated synaptic transmission, since it promotes an increase in the frequency and amplitude of miniature EPSCs (mEPSCs). Together, our results are consistent with a working model in which VASP regulates actin polymerization to promote the development and maturation of spines, allowing for more efficient delivery of receptors to synaptic membranes to potentiate synaptic strength.

Our results raise the question as to how VASP promotes actin assembly in spines to regulate their development. Since the PRD is not required for VASP targeting and function in spines, it seems unlikely that VASP mediates spine formation and maturation through its interaction with profilin. However, we cannot eliminate the possibility that this interaction is important for spine stabilization after stimulation, which may trigger more active spine remodeling (Ackermann and Matus, 2003). Recently, capping protein has been shown to localize throughout dendritic spines (Korobova and Svitkina, 2010). Since VASP family proteins can promote actin polymerization in the presence of capping protein (Gertler et al., 1996; Barzik et al., 2005), it is plausible that VASP and capping protein antagonistically control actin assembly in spines to regulate their development and maturation. Future studies will be needed to more clearly define the roles of VASP and capping protein in coordinately regulating spine and synaptic function.

\section{Signaling mechanisms underlying structural plasticity of dendritic spines (Ryohei Yasuda)}

To reveal the mechanisms of structural plasticity of spines, we have developed a technique to monitor intracellular signaling in 
individual spines in brain slices using FRET sensors in combination with two-photon fluorescence lifetime imaging microscopy [2pFLIM (Yasuda, 2006)]. Previously we have developed FRET sensor for signaling proteins important for LTP, namely CaMKII (Lee et al., 2009) and Ras (Yasuda et al., 2006; Harvey et al., 2008), and demonstrated that the activity of these proteins can be monitored during spine growth associated with LTP induced in single spines using two-photon glutamate uncaging. Our data demonstrated that both CaMKII and Ras are activated in the stimulated spines. While CaMKII activation was compartmentalized in the stimulated spine, the activity of Ras diffused over $10 \mu \mathrm{m}$ along the dendrite and invades neighboring spines. While CaMKII activation lasted only $\sim 10 \mathrm{~s}$ after cessation of stimulation, Ras activation remains more than $\sim 5 \mathrm{~min}$.

In addition to actin binding proteins, Rho-family GTPases also modulate the spine cytoskeleton. Yet the temporal and spatial orchestration of their signaling potential during synaptic activity is unclear. Recently we developed FRET sensors of Rho GTPase proteins RhoA and Cdc42. Rho GTPase proteins have been implicated in spine morphogenesis (Tashiro and Yuste, 2004) and LTP (Rex et al., 2009). When spine growth was induced, both RhoA and Cdc42 were rapidly activated in the stimulated spine, followed by smaller, persistent activity lasting $>30$ min. Although Cdc42 and RhoA share similar structure and diffusion rate, they displayed different spatial patterns as well as activation time course. Cdc42 activation is restricted to the stimulated spines, while RhoA activation diffuses out of the spine and invades the parent dendrites and surrounding spines. Inhibition of Cdc42 and RhoA signaling causes inhibition of sustained and transient phase of spine growth, respectively. Activation of both RhoA and Cdc42 was dependent on NMDA receptors and CaMKII. $\mathrm{Ca}^{2+}$ elevation in response to glutamate uncaging lasts only for $\sim 0.1 \mathrm{~s}$, which is further integrated by CaMKII over $\sim 10$ s (Lee et al., 2009). Our results indicate that persistent RhoA and Cdc42 activation transfers short CaMKII activation into persistent structural plasticity. In particular, long-lasting, spinespecific Cdc42 activation plays an important role to maintain spine specificity of structural plasticity for long periods.

\section{BDNF regulates synaptogenesis by coordinating the expression of the RhoA inhibitors Par6C and Rnd3 (Gary A. Wayman)}

While actin-binding proteins and Rho-family GTPases clearly regulate important aspects of the spine cytoskeleton, the developmental factors that regulate their expression and activity are not. Previous studies show that cAMP response element-binding (CREB) activity plays a critical role in regulating activitydependent dendritic growth (Redmond et al., 2002; Wayman et al., 2006) and spine formation (spinogenesis) in hippocampal neurons (Marie et al., 2005; Impey et al., 2010). Furthermore, Rac1 signaling is regulated by synaptic activity via CREB induction of microRNA132 and suppression of p250GAP a negative regulator of Rac1 (Vo et al., 2005; Wayman et al., 2008; Impey et al., 2010). Importantly, inactivation of CREB-dependent transcription also completely blocks brain-derived neurotrophic factor (BDNF)-stimulated spinogenesis. Conversely, expression of a constitutively active mutant of CREB (caCREB) phenocopies BDNF effects on spinogenesis. These observations prompted our current work to discover the CREB-dependent genetic program activated by BDNF that regulates spinogenesis.

To identify molecules whose expression was controlled by both BDNF and CREB unbiased CREB-SACO (CREB-serial analysis of chromatin occupancy), CREB-CHIP (CREB- chromatin immunoprecipitation) and RNAseq screens were used. Because RhoA signaling needs to be inhibited before BDNF can stimulate synaptogenesis, efforts were focused on the CREBregulated molecules that negatively regulate RhoA activity. Two RhoA-pathway inhibitors identified in these screens were Par6C (also known as Pard6A) and Rnd3 (also known as RhoE). Par6C is a molecule previously identified by Zhang and Macara (2008) that inhibits RhoA by activating the RhoA-GAP, p190GAP. Rnd3 is a Rho family GTPase that has been previously shown to inhibit RhoA signaling partially through activating p190GAP and partially through inhibition of ROCK (Riento et al., 2005; Chardin, 2006; Komander et al., 2008). Interestingly, Rnd3, unlike other Rho family GTPases, has little or no GTPase activity and thus is constitutively active (Riento et al., 2005). Therefore Rnd3 activity is largely controlled by its expression. We first showed that both Par6C and Rnd3 have CREB docked at their promoters and that their expression is induced by BDNF stimulation in hippocampal neurons. We then found that BDNF-dependent induction of both Par6C and Rnd3 is suppressed by inhibition of CREB function with ACREB (a dominant negative CREB mutant), further supporting the conclusion that they are both BDNF- and CREBregulated genes.

We have found that both Par6C and Rnd3 are essential for BDNF-dependent spinogenesis, as suppression of Par6C or Rnd3 by shRNA constructs completely blocks BDNF-stimulated spine formation. In contrast, overexpression of Par6C or Rnd3 increases dendritic spine density and phenocopies BDNF's effects. The changes we see in the number of dendritic spines appear to reflect changes in the number of functional synapses, as the number of mEPSCs also correlated with changes in spine number. Specifically, BDNF treatment or overexpression of either Par6C or Rnd3 increased the frequency of mEPSCs in our cultured hippocampal neurons. In contrast, targeted knockdown of either Par6C or Rnd3 reduced mEPSC frequency.

Par6C and Rnd3 appear to regulate spinogenesis and synaptogenesis via p190GAP regulation of RhoA, as their effects on spines were blocked by expression of a constitutively active mutant of RhoA or suppression of p190GAP. While the mechanism by which Par6C activates p190GAP remains unknown, since Rnd3 also regulates p190GAP activity, it is intriguing to speculate that they may work together to activate p190GAP.

In summary, our recent work demonstrates that BDNF stimulation of hippocampal neurons increases the expression of two inhibitors of the RhoA signaling cascade, Par6C and Rnd3, via a CREB-dependent pathway. Furthermore, Par6C and Rnd3 are both essential and sufficient to stimulate the formation of new spines and synapses. These discoveries provide further insights into how BDNF regulates dendritic spine formation during development by orchestrating the expression of multiple factors that promote synaptogenesis.

\section{Role for OPHN1 at the hippocampal CA3-CA1 synapse (Linda Van Aelst)}

As discussed above, Rho-GTPase signaling governs both spine development and plasticity. In agreement with this, several of the currently identified genes associated with MR code for effectors and regulators of the Rho family GTPases (van Galen and Ramakers, 2005; Nadif Kasri and Van Aelst, 2008). These include the PAK3 effector; GTPase-activating proteins (GAPs), such as Rho-linked mental retardation protein oligophrenin-1 (OPHN1), WRP/MEGAP/srGAP3, and OCRL1; and guanine nucleotide exchange factors (GEFs), such as ARHGEF6. Recent studies have 
begun to provide insight into how mutations in Rho-linked MR genes could compromise cognitive function.

One example of this is the OPHN1 gene, which encodes a Rho-GAP, and was the first identified Rho-linked MR gene (Billuart et al., 1998). It was initially identified by the analysis of a balanced translocation $t(X ; 12)$ observed in a female patient with mild MR (Bienvenu et al., 1997). Subsequent studies have revealed the presence of OPHN1 mutations in families with MR associated with cerebellar hypoplasia and lateral ventricle enlargement (Tentler et al., 1999; Bergmann et al., 2003; Philip et al., 2003; des Portes et al., 2004; Zanni et al., 2005). Abnormal behavior, impaired language skills, and motor development delays were described for several of the patients. All OPHN1 mutations identified to date have been shown, or predicted, to result in OPHN1 loss of function (Zanni et al., 2005), and interestingly, inactivation of ophn1 in mice has been demonstrated to recapitulate some of the human phenotypes, such as behavioral, social, and cognitive impairments (Khelfaoui et al., 2007).

The OPHN1 protein is highly expressed in the brain, where it is found in neurons of all major regions, including hippocampus and cortex, and is present in axons, dendrites, and spines (Govek et al., 2004; Khelfaoui et al., 2007). Recent studies have begun to unveil the function of OPHN1 at both the presynaptic and postsynaptic sites of the hippocampal CA3-CA1 synapse (Khelfaoui et al., 2007, 2009; Nadif Kasri et al., 2009; NakanoKobayashi et al., 2009). By temporally and spatially manipulating OPHN1 gene expression, we obtained evidence that postsynaptic OPHN1 through its Rho-GAP activity plays a key role in the activity-dependent maturation and plasticity of excitatory synapses by controlling their structural and functional stability. In particular, OPHN1 is recruited or stabilized in dendritic spines by spontaneous activity through the activation of NMDARs. In turn, OPHN1 signaling regulates activity-dependent AMPAR synaptic incorporation and stabilization, as well as maintenance of spine structure, thereby permitting synaptic maturation and plasticity. Consequently, decreased or defective OPHN1 signaling prevents glutamatergic synapse maturation and causes loss of synaptic structure, function, and plasticity (Nadif Kasri et al., 2009). These data indicate that normal activity-driven glutamatergic synapse development is impaired by perturbation of postsynaptic OPHN1 function. Thus, our findings connect genetic perturbation of OPHN1 function to glutamatergic hypofunction, and suggest that defects in early circuitry development are a contributory factor to MR associated with OPHN1 mutations.

With regard to OPHN1 presynaptic function, we found that OPHN1 is important for efficient retrieval of synaptic vesicles (SVs) (Khelfaoui et al., 2009; Nakano-Kobayashi et al., 2009). FM4-64 dye labeling experiments showed that the rate of endocytosis was significantly reduced in hippocampal neurons in which OPHN1 was silenced by RNA interference. Also, presynaptic OPHN1 knockdown impaired the efficacy of synaptic transmission under high-frequency stimulation, indicating that presynaptic OPHN1 is important for maintaining synaptic efficacy during repetitive firing at hippocampal synapses. Insight into the mechanism by which OPHN1 controls SV retrieval came from the finding that OPHN1 forms a complex with endophilin $\mathrm{A} 1$, a protein implicated in membrane curvature generation during SV endocytosis. Importantly, OPHN1 mutants defective in endophilin A1 binding, or with impaired Rho-GAP activity, failed to substitute for wild-type OPHN1, indicating that OPHN1's interactions with endophilin A1 and Rho GTPases are important for its function in SV endocytosis. These findings sug- gest that also defects in efficient SV retrieval may contribute to the pathogenesis of OPHN1-linked cognitive impairment.

\section{Regulation of spine formation and function by the candidate MR gene WRP (Scott H. Soderling)}

A second and more recently identified example of a MR linked Rho-family GAP is the WAVE-associated Rac GAP (WRP) (also known as MEGAP and srGAP3) (Endris et al., 2002; Soderling et al., 2002). WAVE-1 functions as an activator of Arp $2 / 3$ in neurons and is enriched in dendritic spines. Proteomic analysis of WAVE-1-associated proteins identified WRP as a binding partner of WAVE-1 and a regulator of Rac and WAVE- 1 signaling in neurons (Soderling et al., 2002). Genetic analysis in mice revealed that WAVE-1 regulates spine density and function, including long-term potentiation and depression (Soderling et al., 2007). Disruption of WAVE-1 in mice also resulted in multiple behavioral abnormalities, including deficits in locomotor skills and spatial and nonspatial learning and memory processes (Soderling et al., 2003). WRP has also been identified as a putative MR gene in humans. A balanced chromosomal translocation within the chromosomal region 3p25 from an individual with severe mental retardation selectively disrupts the coding region of $W R P$ (Endris et al., 2002). This observation indicated that WRP (MEGAP in this study) is linked to mental retardation in humans. Interestingly, interstitial deletions spanning the chromosomal region 3 p25-p26 are referred to as 3p- syndrome and are almost always associated with mental retardation (Shuib et al., 2009). The severity of the phenotypes associated with microdeletions of 3 p25 can be variable and often encompass multiple genes, including WRP, CHL1/CALL, CNTN4, LRRN1, and ITPR1 (Angeloni et al., 1999; Higgins et al., 2000; Fernandez et al., 2008a,b). A recent single nucleotide polymorphism array-based analysis of 14 patients with deletions of $3 \mathrm{p} 25$ suggests that WRP (srGAP3 in this study) maps within the candidate region, whereas other genes fall outside the candidate mental retardation interval (Shuib et al., 2009).

Although several lines of evidence suggest that WRP may modulate key aspects of neuronal development, little is known about how it may contribute to neuronal development. In addition to the GAP domain, which regulates Rac activity, WRP and its related srGAP family members have a conserved N-terminal Fes and CIP4 homology BAR-like (F-BAR) domain, which induces membrane invagination (Itoh et al., 2005; Aspenström, 2009). Surprisingly, a recent study of the related srGAP2 showed that its F-BAR domain enhances outward membrane protrusions that appear similar to that of filopodia (Guerrier et al., 2009). Because the membrane topology facilitated by the F-BAR domain of srGAP2 is opposite of other F-BAR domains, it has been termed an inverse F-BAR or IF-BAR domain (Carlson and Soderling, 2009). Yet what the physiological function of this domain is remains very unclear.

Recently, our group has analyzed the role of WRP during neuronal development. These studies show that WRP plays an important role during dendritic filopodial formation, a key first step during spinogenesis (Ziv and Smith, 1996; Yoshihara et al., 2009). WRP is enriched in dendritic filopodia, and the IF-BAR domain mediates this local targeting of WRP by binding to specific membrane lipids. Interestingly, the WRP IF-BAR domain forms patches on the shafts of dendrites, from which filopodia arise. These clusters are analogous to patches of actin recently reported by EM analysis (Korobova and Svitkina, 2010) and likely represent nascent sites of actin and membrane remodeling that facilitates filopodial emergence. Loss of WRP leads to a re- 
duction in dendritic filopodia and consequently a significant reduction in fully developed spines both in vitro and in vivo. Conditional loss of WRP shows that it is not important for spine maintenance, but is critical during spinogenesis initiation. These studies provide new insights into how an actin signaling molecule also regulates changes in membrane topology during initial spine formation. Finally, behavioral analysis of WRP null mice supports a link between WRP in humans and cognitive dysfunction.

\section{Summary}

To summarize, new insights into spine biology are rapidly emerging on multiple fronts. These include how cytoskeletal and membrane remodeling facilitate spinogenesis as well as how growth factors coordinate the expression of actin regulators during new spine growth. In mature spines, we are finally starting to understand the dynamics and functions of Rho family signaling/regulation and actin-binding proteins during synaptic plasticity. Human genetic studies have implicated components of these pathways as genes involved in mental retardation, and several of these are now being analyzed in model systems. As hoped, these studies are shedding light on both the development and the plasticity of spines as well as how disruptions to these MR associated genes alter animal behavior. Because multiple signaling pathways appear to coordinately govern the spine cytoskeleton, a future challenge will be to understand these pathways at a synaptic systems level.

\section{References}

Ackermann M, Matus A (2003) Activity-induced targeting of profilin and stabilization of dendritic spine morphology. Nat Neurosci 6:1194-1200.

Angeloni D, Lindor NM, Pack S, Latif F, Wei MH, Lerman MI (1999) CALL gene is haploinsufficient in a 3p- syndrome patient. Am J Med Genet 86:482-485.

Applewhite DA, Barzik M, Kojima S, Svitkina TM, Gertler FB, Borisy GG (2007) Ena/VASP proteins have an anti-capping independent function in filopodia formation. Mol Biol Cell 18:2579-2591.

Aspenström P (2009) Roles of F-BAR/PCH proteins in the regulation of membrane dynamics and actin reorganization. Int Rev Cell Mol Biol 272:1-31.

Barzik M, Kotova TI, Higgs HN, Hazelwood L, Hanein D, Gertler FB, Schafer DA (2005) Ena/VASP proteins enhance actin polymerization in the presence of barbed end capping proteins. J Biol Chem 280:28653-28662.

Bear JE, Loureiro JJ, Libova I, Fässler R, Wehland J, Gertler FB (2000) Negative regulation of fibroblast motility by Ena/VASP proteins. Cell 101:717-728.

Bergmann C, Zerres K, Senderek J, Rudnik-Schoneborn S, Eggermann T, Häusler M, Mull M, Ramaekers VT (2003) Oligophrenin 1 (OPHN1) gene mutation causes syndromic X-linked mental retardation with epilepsy, rostral ventricular enlargement and cerebellar hypoplasia. Brain 126:1537-1544

Bienvenu T, Der-Sarkissian H, Billuart P, Tissot M, Des Portes V, Brüls T, Chabrolle JP, Chauveau P, Cherry M, Kahn A, Cohen D, Beldjord C, Chelly J, Cherif D (1997) Mapping of the X-breakpoint involved in a balanced X;12 translocation in a female with mild mental retardation. Eur J Hum Genet 5:105-109.

Billuart P, Bienvenu T, Ronce N, des Portes V, Vinet MC, Zemni R, Carrié A, Beldjord C, Kahn A, Moraine C, Chelly J (1998) Oligophrenin 1 encodes a rho-GAP protein involved in X-linked mental retardation. Pathol Biol (Paris) 46:678.

Bourne JN, Harris KM (2008) Balancing structure and function at hippocampal dendritic spines. Annu Rev Neurosci 31:47-67.

Carlson B, Soderling SH (2009) Mechanisms of cellular protrusions branch out. Dev Cell 17:307-309.

Chardin P (2006) Function and regulation of Rnd proteins. Nat Rev Mol Cell Biol 7:54-62.

Chhabra ES, Higgs HN (2007) The many faces of actin: matching assembly factors with cellular structures. Nat Cell Biol 9:1110-1121.

Cingolani LA, Thalhammer A, Yu LM, Catalano M, Ramos T, Colicos MA,
Goda Y (2008) Activity-dependent regulation of synaptic AMPA receptor composition and abundance by beta3 integrins. Neuron 58:749-762.

des Portes V, Boddaert N, Sacco S, Briault S, Maincent K, Bahi N, Gomot M, Ronce N, Bursztyn J, Adamsbaum C, Zilbovicius M, Chelly J, Moraine C (2004) Specific clinical and brain MRI features in mentally retarded patients with mutations in the Oligophrenin-1 gene. Am J Med Genet A 124A:364-371.

Endris V, Wogatzky B, Leimer U, Bartsch D, Zatyka M, Latif F, Maher ER, Tariverdian G, Kirsch S, Karch D, Rappold GA (2002) The novel RhoGTPase activating gene MEGAP/ srGAP3 has a putative role in severe mental retardation. Proc Natl Acad Sci U S A 99:11754-11759.

Ethell IM, Pasquale EB (2005) Molecular mechanisms of dendritic spine development and remodeling. Prog Neurobiol 75:161-205.

Fernandez T, Morgan T, Davis N, Klin A, Morris A, Farhi A, Lifton RP, State MW (2008a) Disruption of Contactin 4 (CNTN4) results in developmental delay and other features of $3 p$ deletion syndrome. Am J Hum Genet 82:1385.

Fernandez TV, García-González IJ, Mason CE, Hernández-Zaragoza G, Ledezma-Rodríguez VC, Anguiano-Alvarez VM, E’Vega R, GutiérrezAngulo M, Maya ML, García-Bejarano HE, González-Cruz M, Barrios S, Atorga R, López-Cardona MG, Armendariz-Borunda J, State MW, Dávalos NO (2008b) Molecular characterization of a patient with 3p deletion syndrome and a review of the literature. Am J Med Genet A 146A:2746-2752

Gertler FB, Niebuhr K, Reinhard M, Wehland J, Soriano P (1996) Mena, a relative of VASP and Drosophila Enabled, is implicated in the control of microfilament dynamics. Cell 87:227-239.

Govek EE, Newey SE, Akerman CJ, Cross JR, Van der Veken L, Van Aelst L (2004) The X-linked mental retardation protein oligophrenin-1 is required for dendritic spine morphogenesis. Nat Neurosci 7:364-372.

Guerrier S, Coutinho-Budd J, Sassa T, Gresset A, Jordan NV, Chen K, Jin WL, Frost A, Polleux F (2009) The F-BAR domain of srGAP2 induces membrane protrusions required for neuronal migration and morphogenesis. Cell 138:990-1004.

Halpain S (2000) Actin and the agile spine: how and why do dendritic spines dance? Trends Neurosci 23:141-146.

Harvey CD, Yasuda R, Zhong H, Svoboda K (2008) The spread of Ras activity triggered by activation of a single dendritic spine. Science 321:136-140.

Hering H, Sheng M (2001) Dendritic spines: structure, dynamics and regulation. Nat Rev Neurosci 2:880-888.

Higgins JJ, Rosen DR, Loveless JM, Clyman JC, Grau MJ (2000) A gene for nonsyndromic mental retardation maps to chromosome 3p25-pter. Neurology 55:335-340.

Hotulainen P, Llano O, Smirnov S, Tanhuanpää K, Faix J, Rivera C, Lappalainen P (2009) Defining mechanisms of actin polymerization and depolymerization during dendritic spine morphogenesis. J Cell Biol 185:323-339.

Ikeda Y, Dick KA, Weatherspoon MR, Gincel D, Armbrust KR, Dalton JC, Stevanin G, Dürr A, Zühlke C, Bürk K, Clark HB, Brice A, Rothstein JD Schut LJ, Day JW, Ranum LP (2006) Spectrin mutations cause spinocerebellar ataxia type 5. Nat Genet 38:184-190.

Impey S, Davare M, Lasiek A, Fortin D, Ando H, Varlamova O, Obrietan K, Soderling TR, Goodman RH, Wayman GA (2010) An activity-induced microRNA controls dendritic spine formation by regulating Racl-PAK signaling. Mol Cell Neurosci 43:146-156.

Itoh T, Erdmann KS, Roux A, Habermann B, Werner H, De Camilli P (2005) Dynamin and the actin cytoskeleton cooperatively regulate plasma membrane invagination by BAR and F-BAR proteins. Dev Cell 9:791-804.

Kang F, Laine RO, Bubb MR, Southwick FS, Purich DL (1997) Profilin interacts with the Gly-Pro-Pro-Pro-Pro-Pro sequences of vasodilatorstimulated phosphoprotein (VASP): implications for actin-based Listeria motility. Biochemistry 36:8384-8392.

Kasai H, Matsuzaki M, Noguchi J, Yasumatsu N, Nakahara H (2003) Structure-stability-function relationships of dendritic spines. Trends Neurosci 26:360-368.

Khelfaoui M, Denis C, van Galen E, de Bock F, Schmitt A, Houbron C, Morice E, Giros B, Ramakers G, Fagni L, Chelly J, Nosten-Bertrand M, Billuart P (2007) Loss of X-linked mental retardation gene oligophrenin1 in mice impairs spatial memory and leads to ventricular enlargement and dendritic spine immaturity. J Neurosci 27:9439-9450.

Khelfaoui M, Pavlowsky A, Powell AD, Valnegri P, Cheong KW, Blandin Y, 
Passafaro M, Jefferys JG, Chelly J, Billuart P (2009) Inhibition of RhoA pathway rescues the endocytosis defects in Oligophrenin 1 mouse model of mental retardation. Hum Mol Genet 18:2575-2583.

Komander D, Garg R, Wan PT, Ridley AJ, Barford D (2008) Mechanism of multi-site phosphorylation from a ROCK-I:RhoE complex structure. EMBO J 27:3175-3185.

Kopec CD, Li B, Wei W, Boehm J, Malinow R (2006) Glutamate receptor exocytosis and spine enlargement during chemically induced long-term potentiation. J Neurosci 26:2000-2009.

Korobova F, Svitkina T (2010) Molecular architecture of synaptic actin cytoskeleton in hippocampal neurons reveals a mechanism of dendritic spine morphogenesis. Mol Biol Cell 21:165-176.

Lee SJ, Escobedo-Lozoya Y, Szatmari EM, Yasuda R (2009) Activation of CaMKII in single dendritic spines during long-term potentiation. Nature 458:299-304.

Lin WH, Nebhan CA, Anderson BR, Webb DJ (2010) Vasodilatorstimulated phosphoprotein (VASP) induces actin assembly in dendritic spines to promote their development and potentiate synaptic strength. J Biol Chem 285:36010-36020.

Marie H, Morishita W, Yu X, Calakos N, Malenka RC (2005) Generation of silent synapses by acute in vivo expression of CaMKIV and CREB. Neuron 45:741-752.

Matsuzaki M, Honkura N, Ellis-Davies GC, Kasai H (2004) Structural basis of long-term potentiation in single dendritic spines. Nature 429:761-766.

Matus A (2000) Actin-based plasticity in dendritic spines. Science 290:754-758.

Nadif Kasri N, Van Aelst L (2008) Rho-linked genes and neurological disorders. Pflugers Arch 455:787-797.

Nadif Kasri N, Nakano-Kobayashi A, Malinow R, Li B, Van Aelst L (2009) The Rho-linked mental retardation protein oligophrenin-1 controls synapse maturation and plasticity by stabilizing AMPA receptors. Genes Dev 23:1289-1302.

Nakano-Kobayashi A, Kasri NN, Newey SE, Van Aelst L (2009) The Rholinked mental retardation protein OPHN1 controls synaptic vesicle endocytosis via endophilin A1. Curr Biol 19:1133-1139.

Newey SE, Velamoor V, Govek EE, Van Aelst L (2005) Rho GTPases, dendritic structure, and mental retardation. J Neurobiol 64:58-74.

Nimchinsky EA, Sabatini BL, Svoboda K (2002) Structure and function of dendritic spines. Annu Rev Physiol 64:313-353.

Okada H, Soderling SH (2009) Signaling through actin to regulate spine formation and function. Open Neurosci J 3:97-107.

Okamoto K, Nagai T, Miyawaki A, Hayashi Y (2004) Rapid and persistent modulation of actin dynamics regulates postsynaptic reorganization underlying bidirectional plasticity. Nat Neurosci 7:1104-1112.

Philip N, Chabrol B, Lossi AM, Cardoso C, Guerrini R, Dobyns WB, Raybaud C, Villard L (2003) Mutations in the oligophrenin-1 gene (OPHN1) cause X linked congenital cerebellar hypoplasia. J Med Genet 40:441-446.

Ramakers GJ (2002) Rho proteins, mental retardation and the cellular basis of cognition. Trends Neurosci 25:191-199.

Rao A, Craig AM (2000) Signaling between the actin cytoskeleton and the postsynaptic density of dendritic spines. Hippocampus 10:527-541.

Redmond L, Kashani AH, Ghosh A (2002) Calcium regulation of dendritic growth via CaM kinase IV and CREB-mediated transcription. Neuron 34:999-1010.

Reinhard M, Giehl K, Abel K, Haffner C, Jarchau T, Hoppe V, Jockusch BM, Walter U (1995) The proline-rich focal adhesion and microfilament protein VASP is a ligand for profilins. EMBO J 14:1583-1589.

Rex CS, Chen LY, Sharma A, Liu J, Babayan AH, Gall CM, Lynch G (2009) Different Rho GTPase-dependent signaling pathways initiate sequential steps in the consolidation of long-term potentiation. J Cell Biol 186:85-97.

Riento K, Villalonga P, Garg R, Ridley A (2005) Function and regulation of RhoE. Biochem Soc Trans 33:649-651.

Shuib S, McMullan D, Rattenberry E, Barber RM, Rahman F, Zatyka M,
Chapman C, Macdonald F, Latif F, Davison V, Maher ER (2009) Microarray based analysis of 3p25-p26 deletions (3p-syndrome). Am J Med Genet A 149A:2099-2105.

Soderling SH, Binns KL, Wayman GA, Davee SM, Ong SH, Pawson T, Scott JD (2002) The WRP component of the WAVE-1 complex attenuates Rac-mediated signalling. Nat Cell Biol 4:970-975.

Soderling SH, Langeberg LK, Soderling JA, Davee SM, Simerly R, Raber J, Scott JD (2003) Loss of WAVE-1 causes sensorimotor retardation and reduced learning and memory in mice. Proc Natl Acad Sci USA 100:1723-1728.

Soderling SH, Guire ES, Kaech S, White J, Zhang F, Schutz K, Langeberg LK, Banker G, Raber J, Scott JD (2007) A WAVE-1 and WRP signaling complex regulates spine density, synaptic plasticity, and memory. J Neurosci 27:355-365.

Stankewich MC, Gwynn B, Ardito T, Ji L, Kim J, Robledo RF, Lux SE, Peters LL, Morrow JS (2010) Targeted deletion of betaIII spectrin impairs synaptogenesis and generates ataxic and seizure phenotypes. Proc Natl Acad Sci U S A 107:6022-6027.

Tada T, Sheng M (2006) Molecular mechanisms of dendritic spine morphogenesis. Curr Opin Neurobiol 16:95-101.

Tashiro A, Yuste R (2004) Regulation of dendritic spine motility and stability by Racl and Rho kinase: evidence for two forms of spine motility. Mol Cell Neurosci 26:429-440.

Tentler D, Gustavsson P, Leisti J, Schueler M, Chelly J, Timonen E, Annerén G, Willard HF, Dahl N (1999) Deletion including the oligophrenin-1 gene associated with enlarged cerebral ventricles, cerebellar hypoplasia, seizures and ataxia. Eur J Hum Genet 7:541-548.

van Galen EJ, Ramakers GJ (2005) Rho proteins, mental retardation and the neurobiological basis of intelligence. Prog Brain Res 147:295-317.

Vo N, Klein ME, Varlamova O, Keller DM, Yamamoto T, Goodman RH, Impey S (2005) A cAMP-response element binding protein-induced microRNA regulates neuronal morphogenesis. Proc Natl Acad Sci U S A 102:16426-16431.

Wayman GA, Impey S, Marks D, Saneyoshi T, Grant WF, Derkach V, Soderling TR (2006) Activity-dependent dendritic arborization mediated by CaM-kinase I activation and enhanced CREB-dependent transcription of Wnt-2. Neuron 50:897-909.

Wayman GA, Davare M, Ando H, Fortin D, Varlamova O, Cheng HY, Marks D, Obrietan K, Soderling TR, Goodman RH, Impey S (2008) An activity-regulated microRNA controls dendritic plasticity by downregulating p250GAP. Proc Natl Acad Sci U S A 105:9093-9098.

Yasuda R (2006) Imaging spatiotemporal dynamics of neuronal signaling using fluorescence resonance energy transfer and fluorescence lifetime imaging microscopy. Curr Opin Neurobiol 16:551-561.

Yasuda R, Harvey CD, Zhong H, Sobczyk A, van Aelst L, Svoboda K (2006) Supersensitive Ras activation in dendrites and spines revealed by twophoton fluorescence lifetime imaging. Nat Neurosci 9:283-291.

Yoshihara Y, De Roo M, Muller D (2009) Dendritic spine formation and stabilization. Curr Opin Neurobiol 19:146-153.

Yuste R, Bonhoeffer T (2001) Morphological changes in dendritic spines associated with long-term synaptic plasticity. Annu Rev Neurosci 24:1071-1089.

Zanni G, Saillour Y, Nagara M, Billuart P, Castelnau L, Moraine C, Faivre L, Bertini E, Durr A, Guichet A, Rodriguez D, des Portes V, Beldjord C, Chelly J (2005) Oligophrenin 1 mutations frequently cause X-linked mental retardation with cerebellar hypoplasia. Neurology 65:1364-1369.

Zhang H, Macara IG (2008) The PAR-6 polarity protein regulates dendritic spine morphogenesis through p190 RhoGAP and the Rho GTPase. Dev Cell 14:216-226.

Zhou Q, Homma KJ, Poo MM (2004) Shrinkage of dendritic spines associated with long-term depression of hippocampal synapses. Neuron 44:749-757.

Ziv NE, Smith SJ (1996) Evidence for a role of dendritic filopodia in synaptogenesis and spine formation. Neuron 17:91-102. 